\title{
Correction to: CD200 Immune-Checkpoint Peptide Elicits an Anti-glioma Response Through the DAP10 Signaling Pathway
}

\author{
Elisabet Ampudia-Mesias ${ }^{1} \cdot$ Francisco Puerta-Martinez ${ }^{2} \cdot$ Miurel Bridges $^{3}$ - David Zellmer ${ }^{1,4}$. Andrew Janeiro ${ }^{2}$. \\ Matt Strokes $^{5} \cdot$ Yuk Y. Sham $^{3,6}$. Ayman Taher ${ }^{7}$. Maria G. Castro ${ }^{7}$. Christopher L. Moertel ${ }^{1,4} \cdot$ G. Elizabeth Pluhar ${ }^{4,8}$. \\ Michael R. Olin ${ }^{1,4,9}$
}

Published online: 30 April 2021

(c) The American Society for Experimental NeuroTherapeutics, Inc. 2021

\section{Correction to: Neurotherapeutics (2021) https://doi.org/10.1007/s13311-021-01038-1}

This erratum is to update a co-author's name. Maria Castro will be updated to appear as Maria G. Castro.

The original article has been corrected.
Publisher's Note Springer Nature remains neutral with regard to jurisdictional claims in published maps and institutional affiliations.

The original article can be found online at https://doi.org/10.1007/ s13311-021-01038-1.

Michael R. Olin

olin0012@umn.edu

1 Department of Pediatrics, University of Minnesota, Minneapolis, MN 55455, USA

2 Department of Molecular and Computational Biology, University of Southern California, Los Angeles, CA 90089, USA

3 Bioinformatics and Computational Biology Program, University of Minnesota, Minneapolis, MN 55455, USA

4 Masonic Cancer Center, University of Minnesota, Minneapolis, MN 55455, USA
5 Cell Signaling Technology, Inc, Danvers, MA 09123, USA

6 Department of Integrative Biology and Physiology, University of Minnesota, Minneapolis, MN 55455, USA

7 Department of Neurosurgery and Department of Cell and Developmental Biology, University of Michigan Medical School, Ann Arbor, MI 48109, USA

8 Department of Veterinary Clinical Sciences, College of Veterinary Medicine, University of Minnesota, Minneapolis, MN 55455, USA

9 University of Minnesota, 2-167 Moos Tower, 515 Delaware St SE, Minneapolis, MN 55455, USA 